\title{
Lucanus zhanbishengi sp. n., A New Species from Hunan, Central China (Coleoptera: Lucanidae: Lucaninae)
}

\author{
Cheng-Bin Wang ${ }^{1,2}$ \& Xiang $\mathrm{Zhu}^{3}$ \\ 1 Bin Insect Taxonomy Studio, No.16, Xizhaosi Street, Dongcheng District, Beijing 100061, P. R. China \\ 2 Department of Ecology, Faculty of Environmental Sciences, Czech University of Life Sciences Prague, \\ Kamýcká 129, CZ-165 21 Praha 6, Czech Republic \\ 3 Department of Polymer Material Science and Engineering, School of Material Science and Engineering, \\ Jiangsu University, Zhenjiang 212013, P. R. China
}

*Corresponding Author: Cheng-Bin Wang 1,2, Bin Insect Taxonomy Studio, No.16, Xizhaosi Street, Dongcheng District, Beijing 100061, P. R. China

Department of Ecology, Faculty of Environmental Sciences, Czech University of Life Sciences Prague, Kamýcká 129, CZ-165 21 Praha 6, Czech Republic

\begin{abstract}
A new species of stag beetle is described from Hunan, central China, Lucanus zhanbishengi $\mathbf{s p} . \boldsymbol{n}$. (Coleoptera: Lucanidae: Lucaninae). Important morphological characters of the new species and two relative species, L. brivioi Zilioli, 2003 and L. kraatzi Nagel, 1926, are illustrated with color plates.
\end{abstract}

Keywords: China, Lucanidae, Lucaninae, Lucanus, new species, taxonomy

\section{INTRODUCTION}

Lucanus Scopoli, 1763 is the type genus of Lucanidae (Coleoptera) with members distributed in Nearctic, Oriental and Palearctic Regions. However, the genus with the highest diversity in eastern Asia and many species are difficult to identified because of similar habitus. In this decade, Huang \& Chen $(2010,2013,2017)$ excellently revised the Chinese species of Lucanus in their three milestone books which studied on Chinese Lucanidae, Stag beetles of China.

In the present paper, a new species, Lucanus zhanbishengi sp. n., is described and illustrated from Hunan Province, central China. Its diagnosis from congeneric species is provided. And the new species is compared to two related species, L. brivioi Zilioli, 2003 and L. kraatzi Nagel, 1926, with some selected but important morphological characters which are illustrated with color plates.

\section{MATERIALS AND METHODS}

Specimens were relaxed and softened in hot water for 24 hours, and then transferred to distilled water to clean, dissect and observe. In order to examine the genitalia of both sexes, the last two abdominal segments were detached and treated with $10 \%$ solution of potassium hydroxide for 12 hours and then preserved in $75 \%$ ethanol. After examination, the body parts were mounted on a glass slide with Euparal Mounting Medium for future studies. Except photographs of female genitalia in Figure 9 were taken using an Olympus BX53 microscope with an Olympus DP73 camera, other habitus and detail photographs were taken using a Canon macro photo lens MP-E 65mm on a Canon 550D. 
Observations and measurements of morphological details were performed using an Olympus SZX9 stereomicroscope. The final deep focus images were created with Zerene Stacker 1.04 stacking software. Adobe Photoshop CS6 was used for post-processing. The morphological terminology follows Huang \& Chen $(2010,2013,2017)$.

The material examined for this study is deposited in the following collections and museums:

BITS Bin Insect Taxonomy Studio, Beijing, China

CBSZ Collection of Bi-Sheng Zhan, Zhenjiang, China

Measurement criteria in millimeters ( $\mathrm{mm}$ ) are used as follows:

Body length: length from the apex of mandible to the elytral apex.

Elytral length: length from the basal border of elytra to its apex along suture.

Elytral width: widest part of both elytra combined.

Head length: length from the anterior apex of clypeus to the posterior margin along the midline.

Head width: widest part of head.

Mandible length: length from the apex of mandible to its base at anterior margin of the head.

Pronotal length: length of the pronotum along the midline.

Pronotal width: widest part of pronotum.

\section{RESUlTS}

\section{Genus Lucanus Scopoli, 1763}

Vernacular name: 深山锹甲属

\section{Lucanus zhanbishengi sp. n.}

Vernacular name: 詹氏深山锹甲

Figs 1A-C, 2A-C, 3A-B, 4A-D, 5A-D, 6A-I, 8A-B, 9A-C, 10

Material examined. Holotype: $\curvearrowright$, CHINA, Hunan: Hongjiang City, Xuefengshan Nature Reserve [雪峰山自然保护区], Subaoding, 1900 m, 6.VI.2016, Bi-Sheng Zhan leg. (BITS). Paratypes: $9 \widehat{\jmath} 4$ 우우, same data as holotype except 3.VII.2017, Bi-Sheng Zhan \& Xiang Zhu leg. (CBSZ).

Diagnosis. Male: labrum ligulate, anterior ridge of head evenly elevated, lateral ridges of head (Figs $1 \mathrm{~A}-\mathrm{C})$ distinctly protruded, major inner tooth preceded by $6-7$ smaller teeth and followed by $8-11$ smaller teeth that are not continued to the base of mandible, protibia with 15-18 small teeth along outer margin, 8th abdominal tergite (Figs 4A, C) with poorly-defined lateral angles, 8th abdominal ventrite (Figs 4B, D) with large membranous area in the middle, ventral plate of 9th abdominal segment (Figs 5A, C) with thin longitudinal membranous stripe along midline of apical expansion, aedeagus with ventral plate (Figs 6A, F) at apical end of basal piece long, apex of paramere (Figs 6C, H) weakly upcurved, penis (Figs 6A, F) short but wide (about 3/5 length of parameres), flagellum (Figs 6D, G, H) more than twice as long as parameres, apex of flagellum (Figs 6E, I) weakly enlarged; female: pronotum (Fig. 3A) widest behind the middle, elytra (Fig. 3A) clothed with fine pubescence, protibial apex (Fig. 3A) with basal branch much more expanded, 8th abdominal tergite (Fig 8A) with poorly-defined lateral angles, hemisternite (Figs 9A-B) moderately wide and inner lateral margin of sclerotized part long, spermatheca (Fig 9C) with proximal parts slender and turned dorsally, 
Lucanus zhanbishengi sp. n., A New Species from Hunan, Central China (Coleoptera: Lucanidae: Lucaninae)

spermathecal duct (Fig 9A) about 2.5 times as long as spermatheca, spermathecal gland (Fig 9A) cystiform.

Description. Male Holotype. Large size, body $51.9 \mathrm{~mm}$ long. Length $(\mathrm{mm})$ of different body parts: head (6.9) : mandible (21.1) : pronotum (6.0) : elytra (18.5); width (mm): head (13.5) : pronotum (10.8) : elytra (12.8).

Habitus (Figs 1C, 2C): Color mostly blackish brown on both dorsal and ventral surfaces; elytra reddish brown; ventral surface of profemora, both dorsal and ventral surfaces of meso- and metafemora with transverse reddish stripes. Body clothed with fine, recumbent, yellowish pubescence, but markedly longer and denser on metasternum.

Head (Fig 1C). Form transverse. Anterior ridge clearly defined and evenly elevated. Lateral ridges distinctly protruded, forming rounded angles at lateral corners. Clypeolabrum fused with frons, not defined by transverse suture, about 1.4 times as long as wide; labrum ligulate, lacking dorsal branch, simply rounded at apex. Mandible about 3.0 times as long as head, markedly incurved at basal 1/3, then straight to apex; apical fork with upper branch markedly longer than lower branch; major inner tooth slender and longer than width of mandible; major inner tooth preceded by 6-7 smaller teeth and followed by 8-11 smaller teeth that are not continued to the base of mandible. Antennal club with 4 antennomeres; antennomere VII slender and sharply pointed apically; antennomeres VIII-X lamellate.

Legs (Fig 1C). Protibia continuously serrated along outer margin, with 15-18 small teeth of different sizes; apex bifurcate with branches somewhat sharp at tip. Except apical spurs and spines, mesotibia with 3 small lateral spines and metatibia with 2 lateral spines.

Male genitalia. 8th abdominal tergite (Fig 4C) with poorly-defined lateral angles. 8th abdominal ventrite (Fig 4D) with large membranous area in the middle. Ventral plate of 9th abdominal segment (Fig 5C) with thin longitudinal membranous stripe along midline of apical expansion. Aedeagus in dorsal view (Fig 6G) about 2.4 times as long as wide. Basal piece in dorsal view oblong, nearly 1.7 times as long as parameres, with pair of sclerotized dorsal plates; ventral plate (Fig 6F) at apical end of basal piece long, well sclerotized, widely emarginate at apical margin. Paramere with wide basal process; apex (Fig 6H) weakly upcurved. Penis (Fig 6F) short but wide, about 3/5 length of parameres. Flagellum (Figs 6G, H) long, more than twice as long as parameres, apex (Fig 6I) weakly enlarged.

Male paratypes (Figs 1A-B, 2 A-B). Body 49-57 mm long.

Variation. Color: Transverse reddish stripes on ventral surface of profemora, both dorsal and ventral surfaces of meso- and metafemora variable, absent (Fig 2B), narrowly transverse (Fig 2A), or broadened (Fig 2C) . In large-sized males, apical fork of mandible more opened, number of inner teeth more, clypeolabrum longer, anterior ridge of head well elevated, lateral ridges of head distinctly protruded; while in small-sized males, apical fork of mandible less opened, clypeolabrum shorter, anterior ridge of head weakly elevated, lateral ridges of head weakly protruded.

Female paratype. Body $31.0 \mathrm{~mm}$ long. Length $(\mathrm{mm})$ of different body parts: head (3.3) : mandible (3.0) : pronotum (6.0) : elytra (16.7); width (mm): head (7.9) : pronotum (10.5) : elytra (11.7).

Habitus (Figs. 3A-B). Color almost wholy black on both dorsal and ventral surfaces. Body clothed with fine, recumbent, yellowish pubescence, but markedly longer and denser on metasternum.

Head (Fig. 3A). Canthus with both anterior and posterior angles clearly defined; anterior angle inside of eye; lateral margin weakly concave. Anterior and lateral ridges absent. Clypeolabrum transverse, 
Lucanus zhanbishengi sp. n., A New Species from Hunan, Central China (Coleoptera: Lucanidae: Lucaninae)

flat at apex, not protruding medially. Both mandibles with distinct dorsal teeth; inner tooth of right mandible with broad and flat inner ridge; left mandible with 2 widely-separated inner teeth and small gap behind apex, inner margin between teeth long, weakly concave.

Pronotum (Fig. 3A). Form 1.7 times as wide as long, widest behind the middle; anterior angle rounded; lateral angles weakly defined; posterior angle obtuse.

Legs (Fig. 3A). Protibial apex bifurcate, with basal branch much more expanded.

Female genitalia. 8th abdominal tergite (Fig 8A) with poorly-defined lateral angles. 8th abdominal ventrite (Fig 8B) with large membranous area in the middle. Hemisternite (Figs 9A-B) moderately wide, broadly rounded apically, with outer apex not produced beyond inner apex; inner lateral margin of sclerotized part long. Spermatheca (Fig 9A) sclerotized, J-shaped; proximal parts slender and turned dorsally (Fig 9C). Spermathecal duct (Fig 9A) long, about 2.5 times as long as spermatheca. Spermathecal gland (Fig 9A) cystiform, shorter than spermatheca. Central conjunction of 9th tergite protruding medially and narrow at tip.

Field observations. Mating of Lucanus zhanbishengi sp. n. in Xuefengshan Nature Reserve (Hunan) as shown in Fig. 10.

Etymology. The specific epithet is dedicated to Mr. Bi-Sheng Zhan (Jiangsu University, Zhenjiang, Jiangsu, China), one of the collectors of this new species and a good amateur obsessing with beetles.

Distribution. China (Hunnan).

Remarks. This new species should be placed in the Lucanus fortunei group (sensu Huang \& Chen 2010). It well resembles L. brivioi Zilioli, 2003 in general appearance, but it can be distinguished from the latter by the combination of the following characters: in L. zhanbishengi $\mathrm{sp}$. $\mathrm{n}$., male: labrum ligulate, lateral ridges of head (Figs 1A-C) distinctly protruded, major inner tooth preceded by 6-7 smaller teeth and followed by 8-11 smaller teeth, protibia with 15-18 small teeth along outer margin, 8th abdominal ventrite (Figs 4B, D) with large membranous area in the middle, ventral plate of 9th abdominal segment (Figs 5A, C) with thin longitudinal membranous stripe along midline of apical expansion, penis (Figs 6A, F) short but wide (about 3/5 length of parameres), flagellum (Figs 6D, G, $\mathrm{H})$ more than twice as long as parameres; female: elytra (Fig. 3A) clothed with fine pubescence, protibial apex (Fig. 3A) with basal branch much more expanded, hemisternite (Figs 9 A-B) moderately wide and inner lateral margin of sclerotized part long, spermatheca (Fig 9C) with proximal parts slender and turned dorsally, spermathecal duct (Fig 9A) about 2.5 times as long as spermatheca, spermathecal gland (Fig 9A) cystiform. While in L. brivioi Zilioli, male: lateral ridges of head (Fig 1D) moderately protruded, labrum subtriangular, major inner tooth preceded by about 4-5 smaller teeth and followed by about 6-8 smaller teeth, protibia with 9-11 small teeth along outer margin, 8th abdominal ventrite (Fig 4F) without membranous area, ventral plate of 9th abdominal segment (Fig 5E) only with small membranous area at the median of apical part, penis (Fig 7A) long and slender (nearly as long as parameres), flagellum (Figs 7A-C) about 1.4 times as long as parameres; female: elytra (Fig. 3C) glabrous, protibial apex (Fig. 3C) with basal branch weakly expanded, hemisternite (Figs 9A-B) rather wide and inner lateral margin of sclerotized part short, spermatheca (Fig 9F) with proximal parts almost straight, spermathecal duct (Fig 9D) almost as long as spermatheca, spermathecal gland (Fig 9A) vermiform.

This new species is similar to Lucanus kraatzi Nagel, 1926, but it is easily to distinguish them by the combination of the following characteristics: in L. zhanbishengi sp. n., male: labrum ligulate, anterior ridge of head evenly elevated, lateral ridges of head (Figs 1A-C) distinctly protruded, major inner 
tooth preceded by 6-7 smaller teeth and followed by 8-11 smaller teeth, protibia with 15-18 small teeth along outer margin, 8th abdominal tergite (Figs 4A, C) with poorly-defined lateral angles, 8th abdominal ventrite (Figs 4B, D) with large membranous area in the middle, ventral plate of 9th abdominal segment (Figs 5A, C) with thin longitudinal membranous stripe along midline of apical expansion, aedeagus with ventral plate (Figs 6A, F) at apical end of basal piece long, apex of paramere (Figs 6C, H) weakly upcurved, penis (Figs 6A, F) short but wide (about 3/5 length of parameres), flagellum (Figs 6D, G, H) more than twice as long as parameres, apex of flagellum (Figs 6E, I) weakly enlarged; female: elytra (Fig. 3A) clothed with fine pubescence, protibial apex (Fig. 3A) with basal branch much more expanded, 8th abdominal tergite (Fig 8A) with poorly-defined lateral angles, spermatheca (Fig 9C) with proximal parts slender and turned dorsally, spermathecal duct (Fig 9A) about 2.5 times as long as spermatheca. While in L. kraatzi Nagel, labrum subtriangular, anterior ridge of head much more elevated in the middle, lateral ridges of head (Fig 1E) strongly protruded, major inner tooth preceded by about 4 smaller teeth and followed by about 8 smaller teeth, protibia with 2-4 small teeth along outer margin, 8th abdominal tergite (Fig 4G) with well-defined lateral angles, 8th abdominal ventrite (Fig $4 \mathrm{H})$ without membranous area, ventral plate of 9th abdominal segment (Fig 5G) without membranous area, aedeagus with ventral plate (Fig 7E) at apical end of basal piece short, apex of paramere (Fig 7G) strongly upcurved, penis (Fig 7E) long and slender (nearly as long as parameres), flagellum (Figs $7 \mathrm{E}-\mathrm{G}$ ) less than twice as long as parameres, apex of flagellum (Figs 7H) strongly enlarged; female: elytra (Fig. 3E) clothed with strong pubescence, protibial apex (Fig. 3C) with basal branch moderately expanded, 8th abdominal tergite (Fig 8E) with well-defined lateral angles, spermatheca (Fig 9I) with proximal parts inflated and straight, spermathecal duct (Fig 9A) about 0.7 times as long as spermatheca

Lucanus zhanbishengi sp. $\mathrm{n}$. is also somewhat similar to $L$. deuveianus Boucher, 1998 and $L$. hewenjiae Huang \& Chen, 2013 from Guangxi Province, but it is not difficult to distinguish it from them by the combination of characters in the above paragraph of Diagnosis.

\section{Lucanus brivioi Zilioli, 2003}

Vernacular name: 布氏深山锹甲

Figs 1D, 2D, 3C-D, 4E-F, 5E-F, 7A-D, 8C-D, 9D-F

Material examined. $3 \hat{\jmath} \delta^{\lambda}$, , CHINA, Fujian: Quanzhou City, Dehua County, Daiyunshan Nature Reserve, 1500 m, VI.2016, Bi-Sheng Zhan leg. (CBSZ).

Distribution. China (Fujian).

\section{Lucanus kraatzi Nagel, 1926}

Vernacular name: 扩头深山锹甲

Figs 1E, 2E, 3E-F, 4G-H, 5G-H, 7E-H, 8E-F, 9G-I

Material examined. $3 \widehat{\partial} 1$, , CHINA: Yunnan, Qujing City, Tianshengqiao power station, $1700 \mathrm{~m}$, VIII.2016, Yun-Chuan Xu leg. (CBSZ).

Distribution. China (Fujian, Guizhou, Sichuan, Yunnan). 


\section{Figures :}
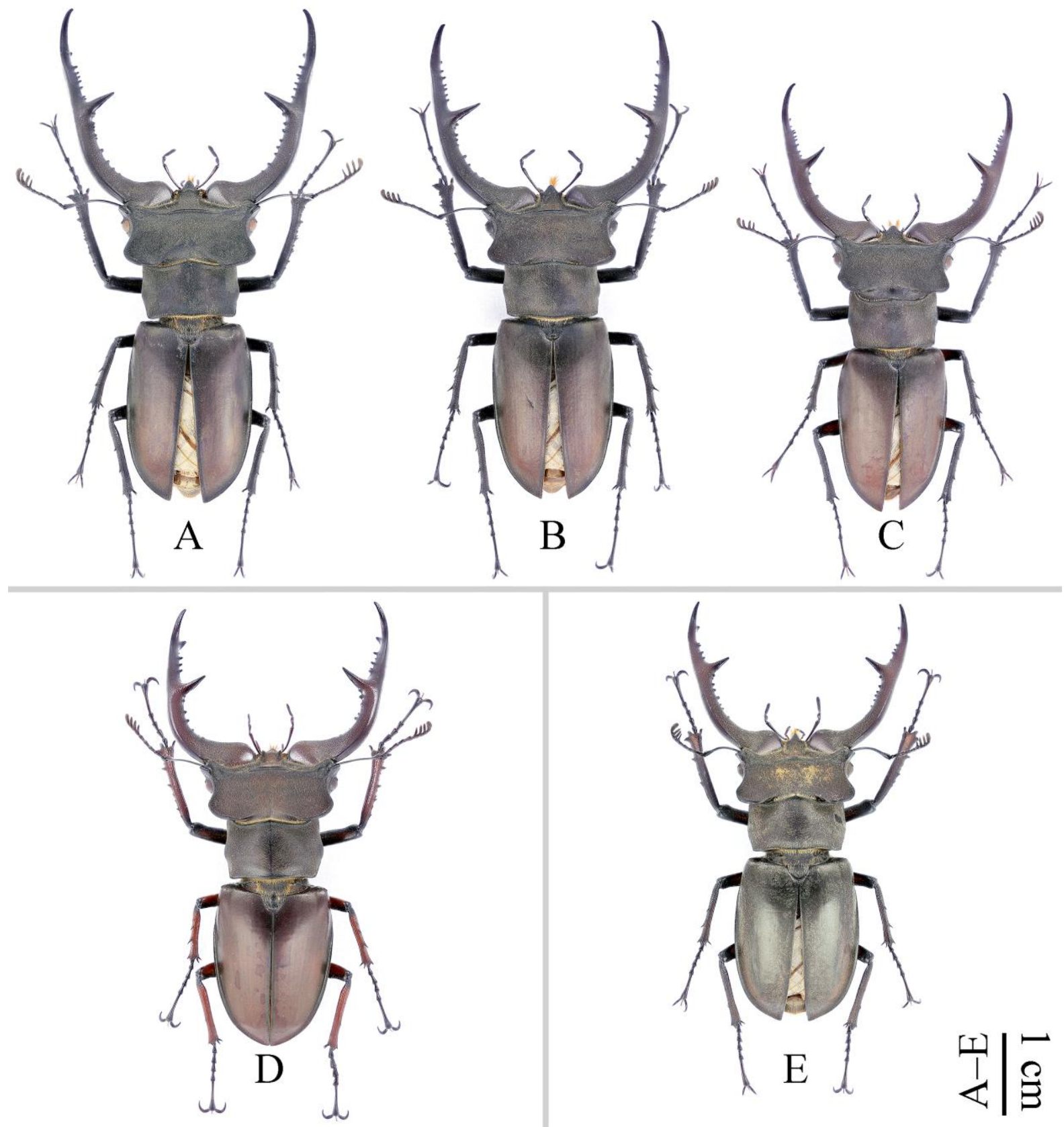

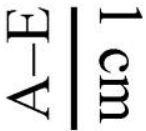

Figure 1. Habitus of Lucanus spp. $\widehat{\partial} \widehat{\partial}$, dorsal view. A-C L. zhanbishengi sp. $n$. A paratype a (Hunan) B paratype b (Hunan) C holotype (Hunan) D L. brivioi Zilioli, 2003 (Fujian) E L. kraatzi Nagel, 1926 (Yunnan). 
Lucanus zhanbishengi sp. n., A New Species from Hunan, Central China (Coleoptera: Lucanidae: Lucaninae)

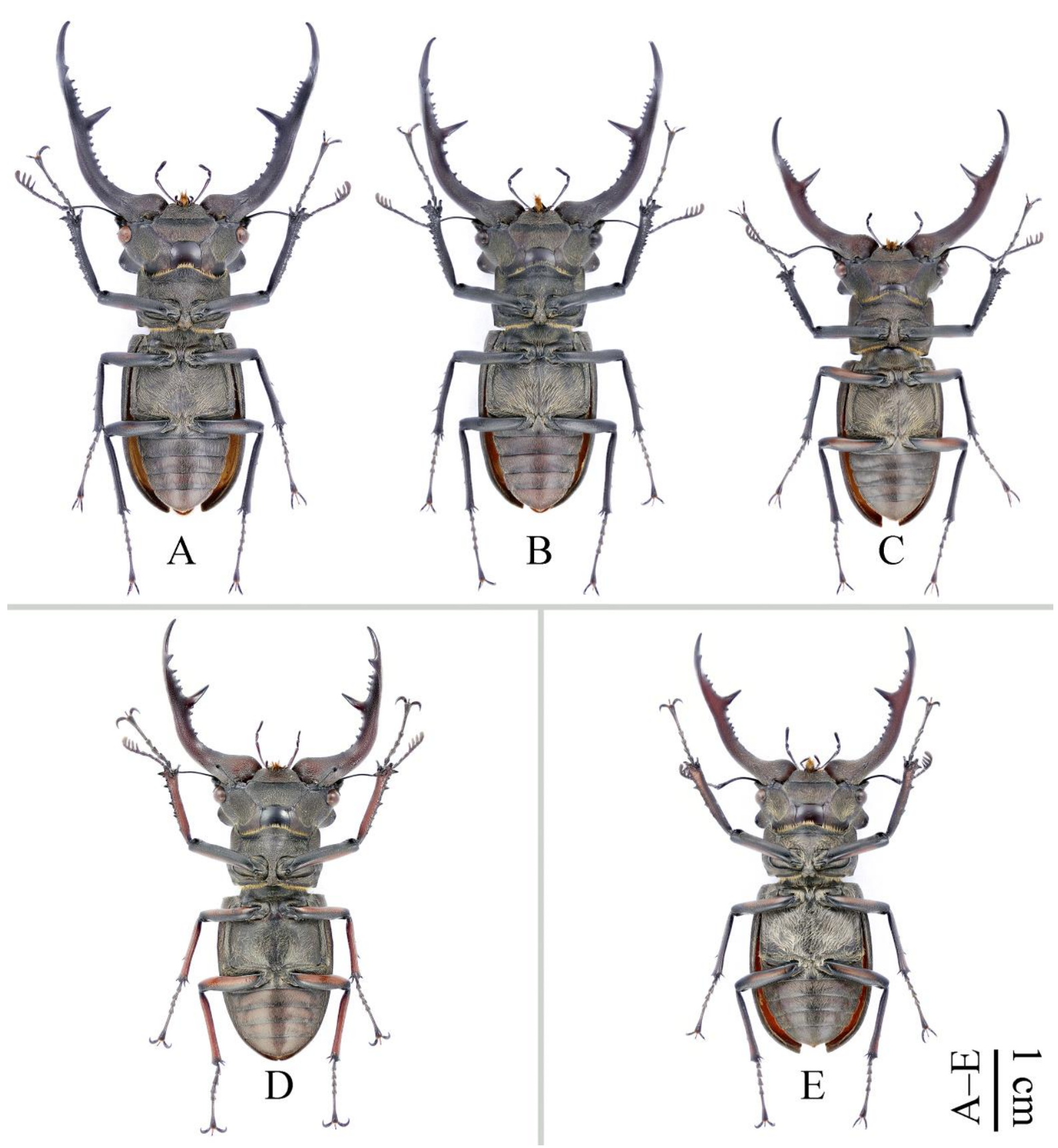

Figure 2. Habitus of Lucanus spp. $\widehat{\partial} \hat{\delta}$, ventral view. $\boldsymbol{A}-\boldsymbol{C}$ L. zhanbishengi sp. n. A paratype a (Hunan) $\boldsymbol{B}$ paratype b (Hunan) C holotype (Hunan) D L. brivioi Zilioli, 2003 (Fujian) E L. kraatzi Nagel, 1926 (Yunnan). 

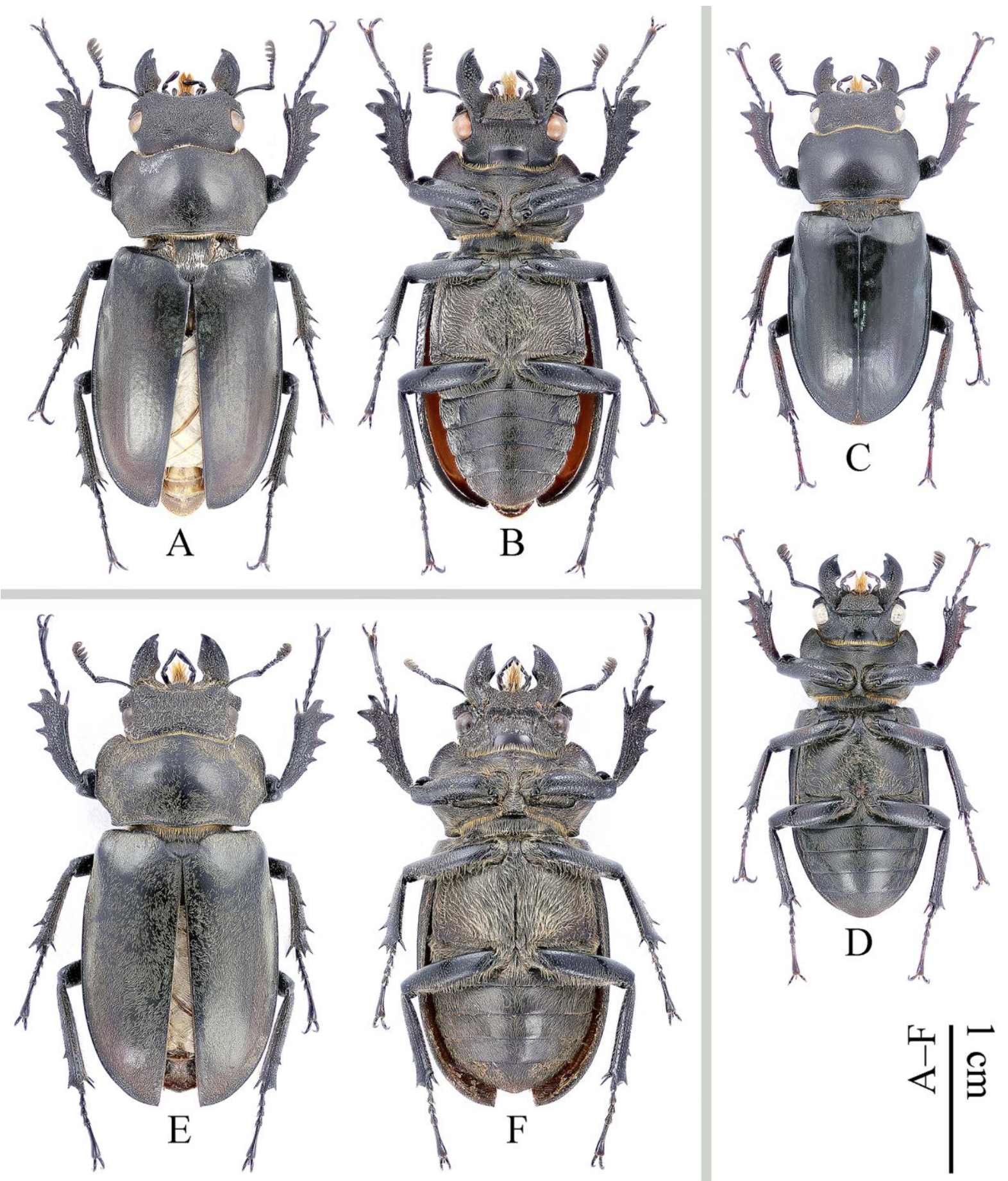

Figure 3. Habitus of Lucanus spp. 우우. A-B L. zhanbishengi sp. n. paratype c (Hunan) $\boldsymbol{C}-\boldsymbol{D}$ L. brivioi Zilioli, 2003 (Fujian) $\boldsymbol{E}-\boldsymbol{F}$ L. kraatzi Nagel, 1926 (Yunnan). A, $\boldsymbol{C}, \boldsymbol{E}$ dorsal view $\boldsymbol{B}, \boldsymbol{D}, \boldsymbol{F}$ ventral view. 
Lucanus zhanbishengi sp. n., A New Species from Hunan, Central China (Coleoptera: Lucanidae: Lucaninae)

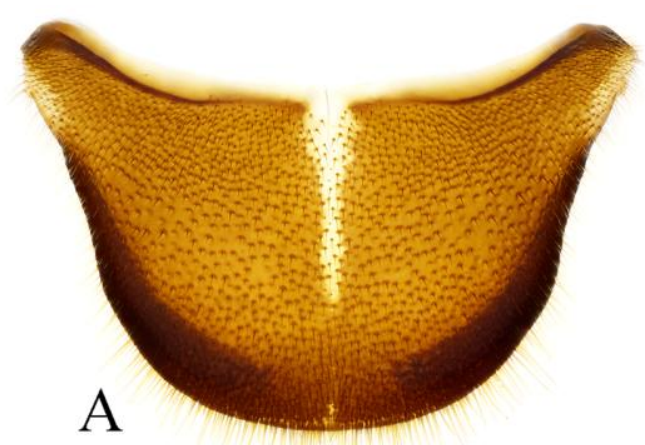

$$
\text { 安志 }
$$
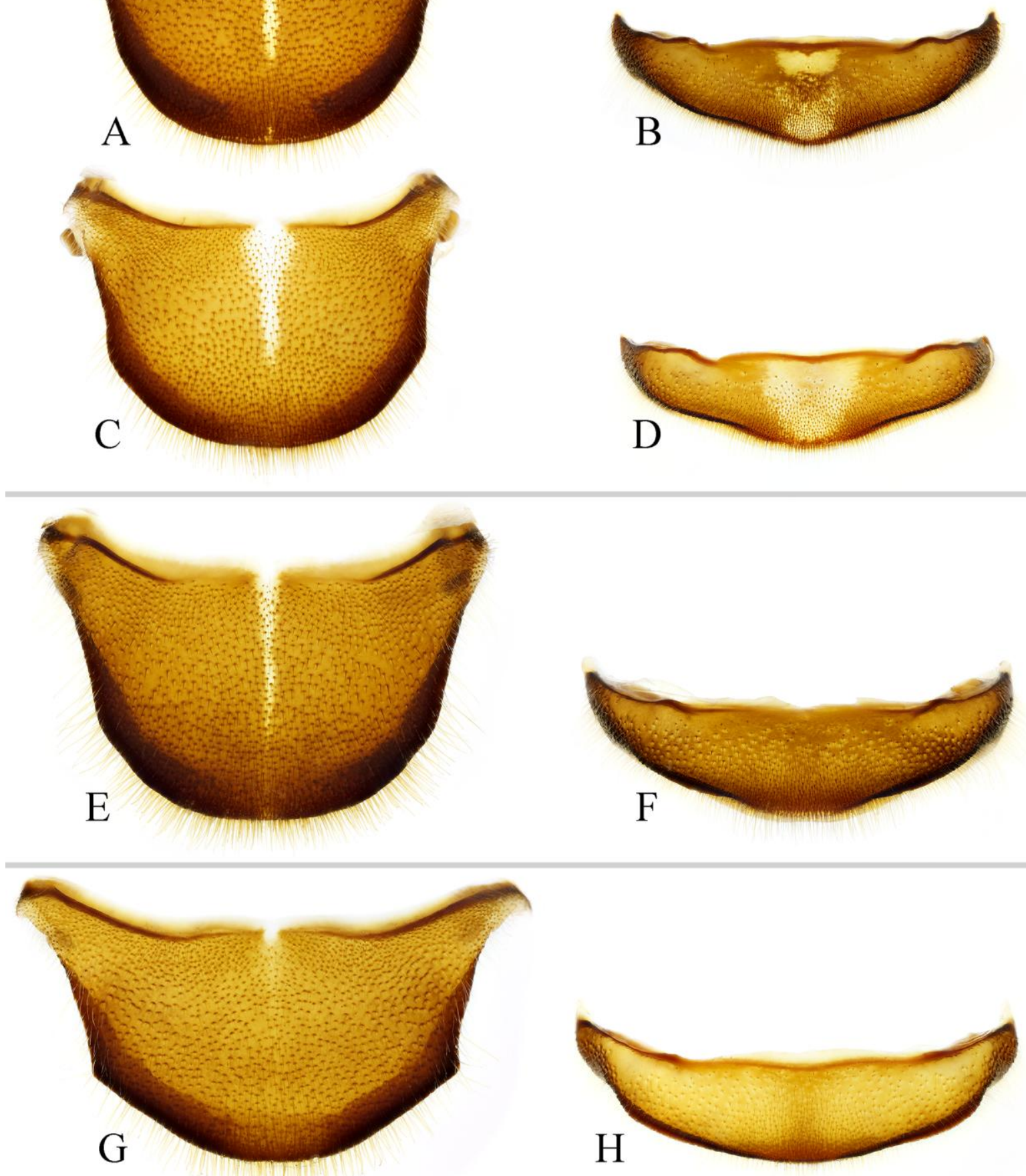

Figure 4. $\boldsymbol{A}, \boldsymbol{C}, \boldsymbol{E}, \boldsymbol{G}$ male 8th abdominal tergites of Lucanus spp., dorsal view $\boldsymbol{B}, \boldsymbol{D}, \boldsymbol{F}, \boldsymbol{H}$ male 8th abdominal ventrites of Lucanus spp., ventral view. $\boldsymbol{A}-\boldsymbol{D}$ L. zhanbishengi sp. $n$. A-B paratype $b$ (Hunan) $\boldsymbol{C}-\boldsymbol{D}$ holotype (Hunan) E-F L. brivioi Zilioli, 2003 (Fujian) G-H L. kraatzi Nagel, 1926 (Yunnan). 
Lucanus zhanbishengi sp. n., A New Species from Hunan, Central China (Coleoptera: Lucanidae: Lucaninae)

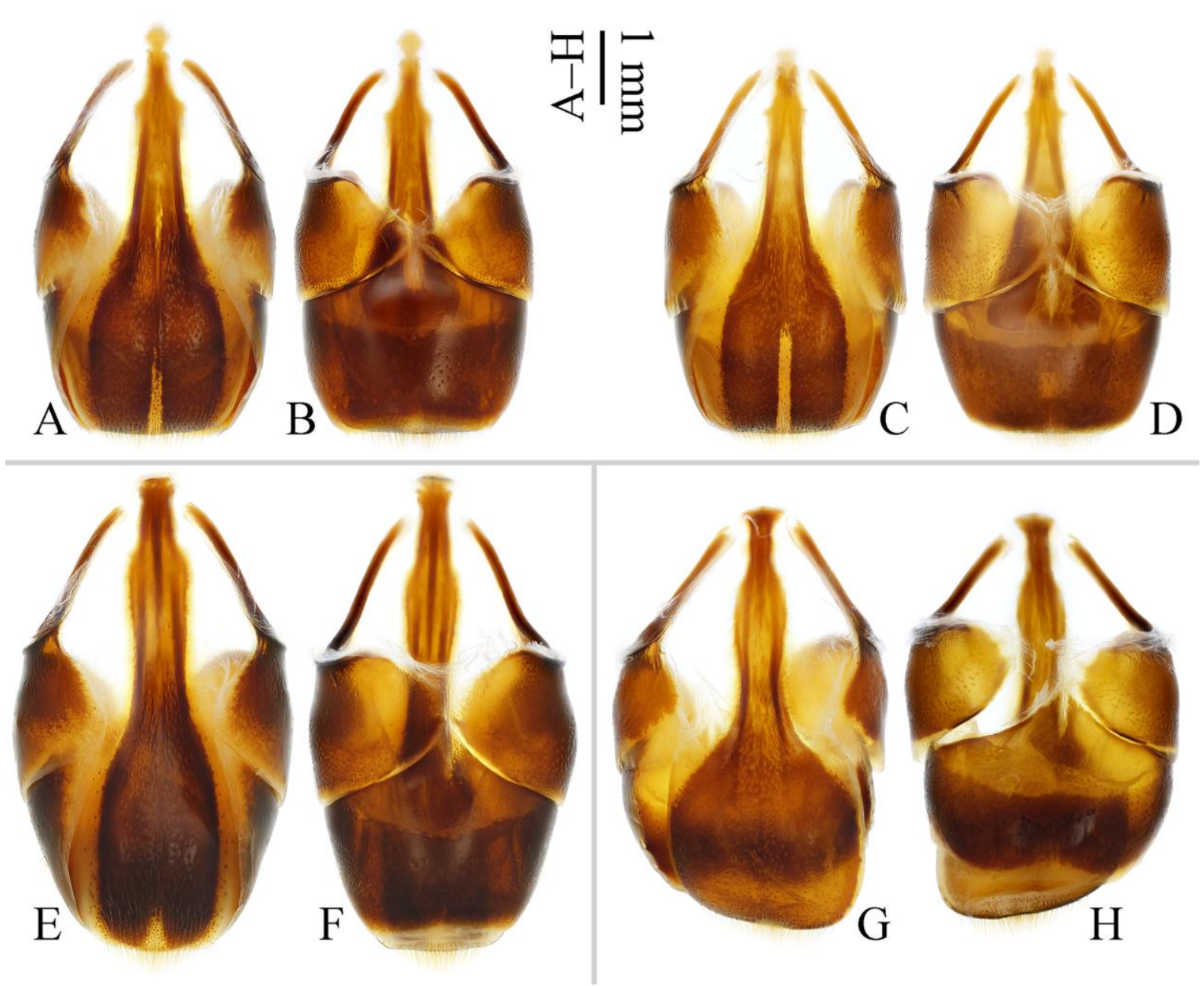

Figure 5. Male 9th abdominal segments of Lucanus spp. A-D L. zhanbishengi sp. $n$. A-B paratype $b$ (Hunan) $\boldsymbol{C}-\boldsymbol{D}$ holotype (Hunan) $\boldsymbol{E}-\boldsymbol{F}$ L. brivioi Zilioli, 2003 (Fujian) $\boldsymbol{G}-\boldsymbol{H}$ L. kraatzi Nagel, 1926 (Yunnan). A, C, E, G ventral view $\boldsymbol{B}, \boldsymbol{D}, \boldsymbol{F}, \boldsymbol{H}$ dorsal view. 
Lucanus zhanbishengi sp. n., A New Species from Hunan, Central China (Coleoptera: Lucanidae: Lucaninae)

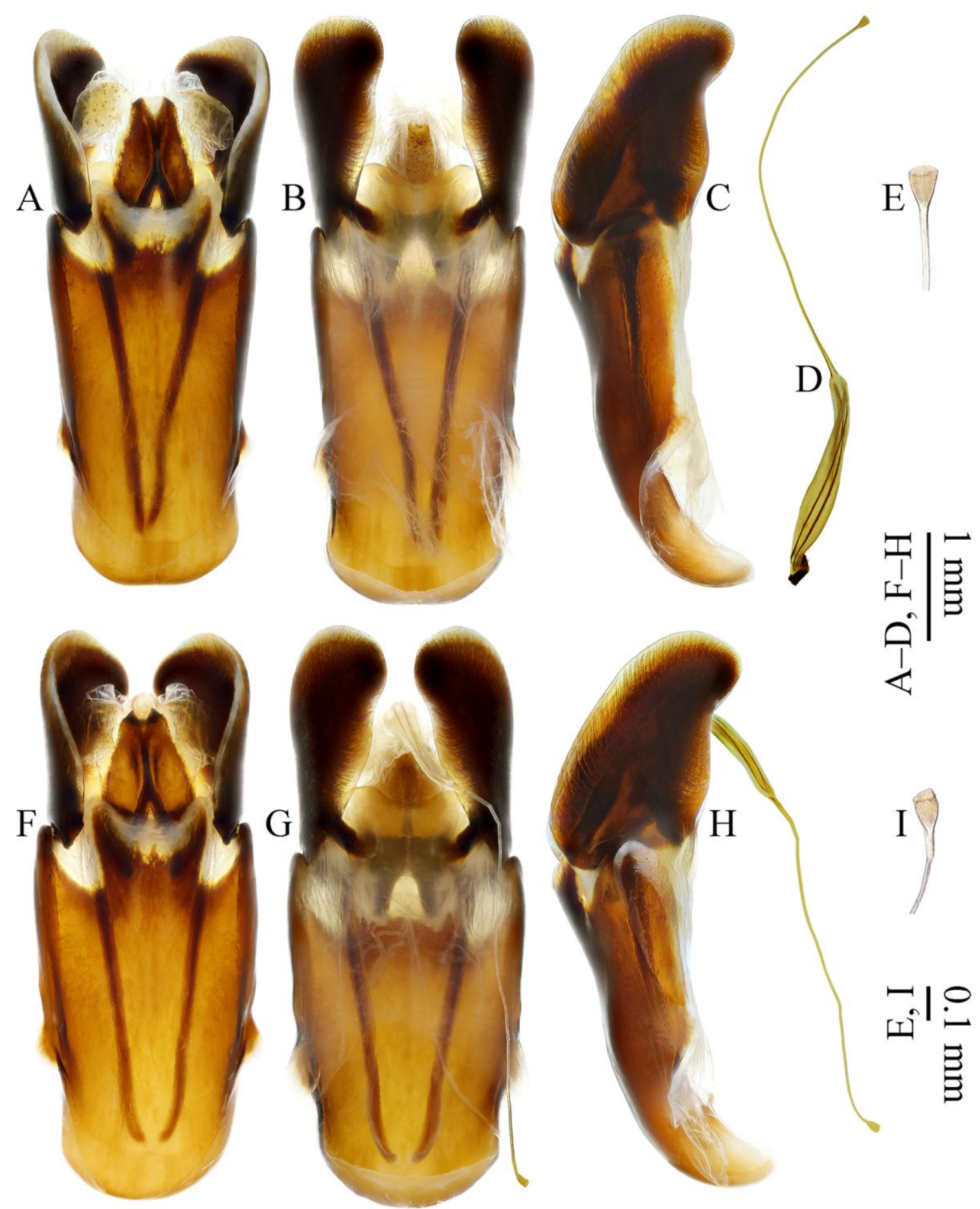

Figure 6. Aedeagi of Lucanus zhanbishengi sp. $n$. (D flagellum $\boldsymbol{E}, \boldsymbol{I}$ apices of flagellum). A-E paratype $b$ (Hunan) $\boldsymbol{F}-\boldsymbol{I}$ holotype (Hunan). A, $\boldsymbol{F}$ ventral view $\boldsymbol{B}, \boldsymbol{D}, \boldsymbol{E}, \boldsymbol{G}, \boldsymbol{I}$ dorsal view $\boldsymbol{C}, \boldsymbol{H}$ lateral view. 
Lucanus zhanbishengi sp. n., A New Species from Hunan, Central China (Coleoptera: Lucanidae: Lucaninae)
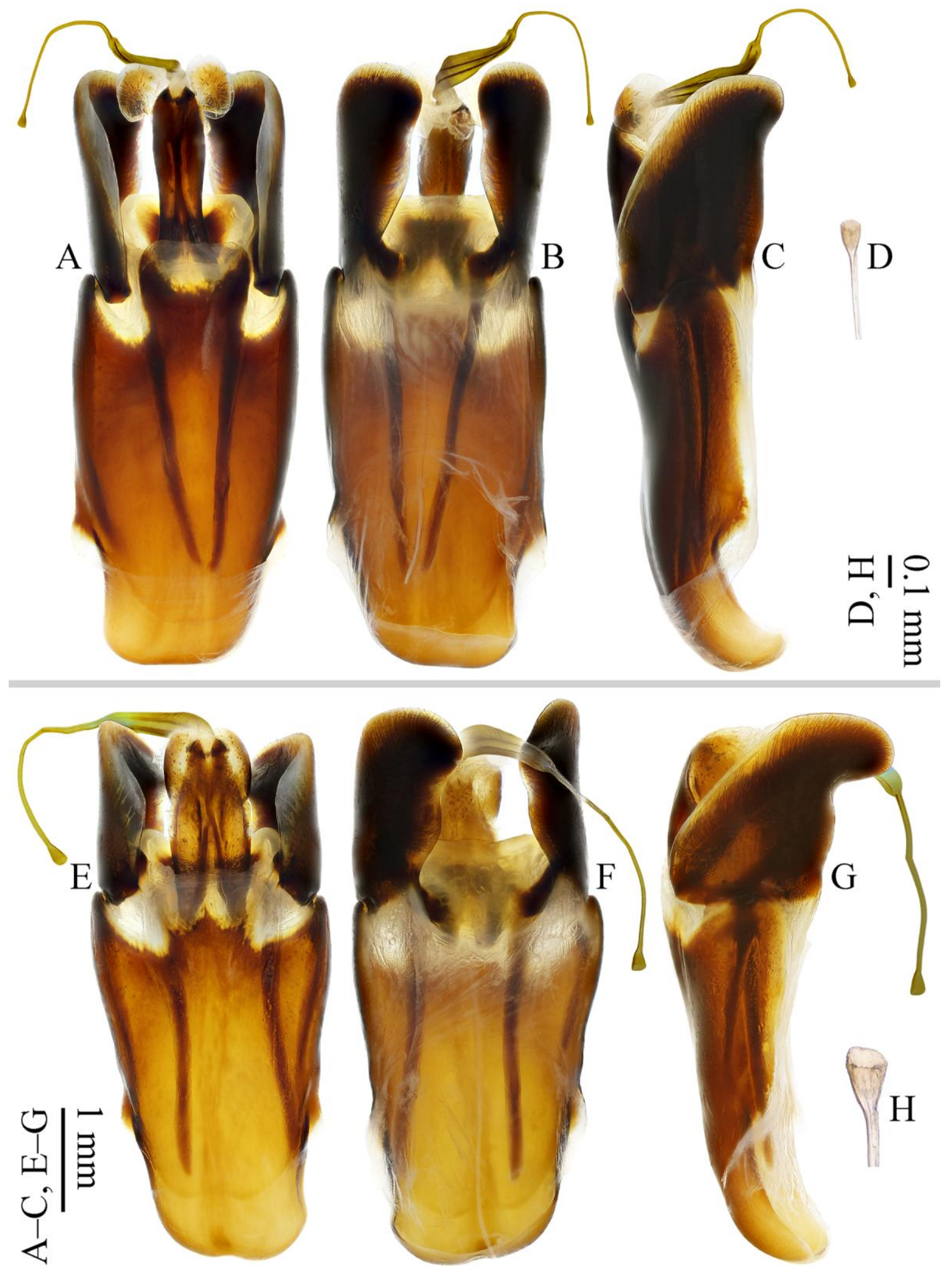

Figure 7. Aedeagi of Lucanus spp. (D, $\boldsymbol{H}$ apices of flagellum). A-D L. brivioi Zilioli, 2003 (Fujian) $\boldsymbol{E}-\boldsymbol{H}$ L. kraatzi Nagel, 1926 (Yunnan). A, $\boldsymbol{E}$ ventral view $\boldsymbol{B}, \boldsymbol{D}, \boldsymbol{F}, \boldsymbol{H}$ dorsal view $\boldsymbol{C}, \boldsymbol{G}$ lateral view. 
Lucanus zhanbishengi sp. n., A New Species from Hunan, Central China (Coleoptera: Lucanidae: Lucaninae)

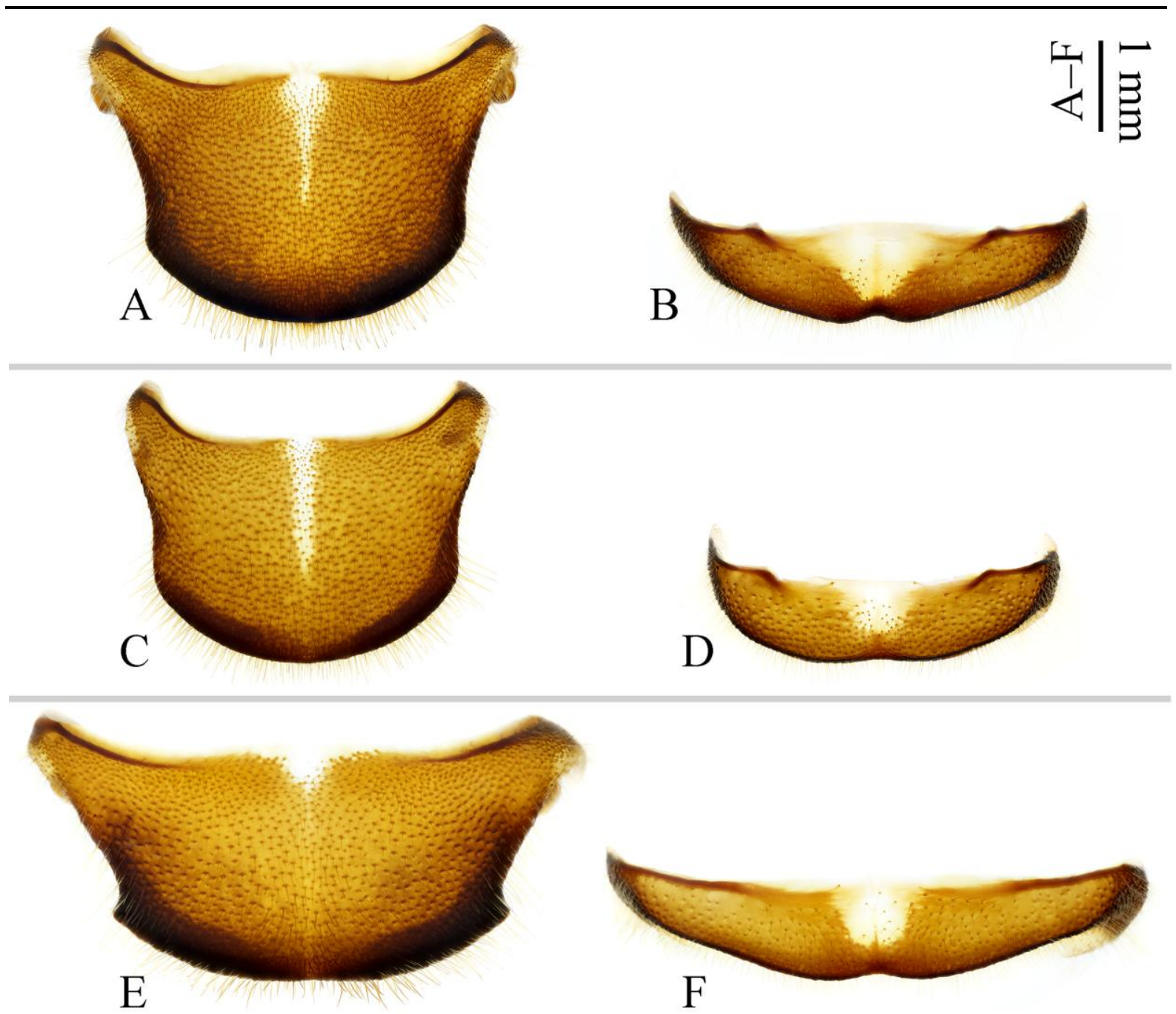

Figure 8. $\boldsymbol{A}, \boldsymbol{C}, \boldsymbol{E}$ female 8th abdominal tergites of Lucanus spp., dorsal view $\boldsymbol{B}, \boldsymbol{D}, \boldsymbol{F}$ female 8th abdominal ventrites of Lucanus spp., ventral view. $\boldsymbol{A}-\boldsymbol{B}$ L. zhanbishengi sp. n. paratype c (Hunan) $\boldsymbol{C}-\boldsymbol{D}$ L. brivioi Zilioli, 2003 (Fujian) E-F L. kraatzi Nagel, 1926 (Yunnan). 


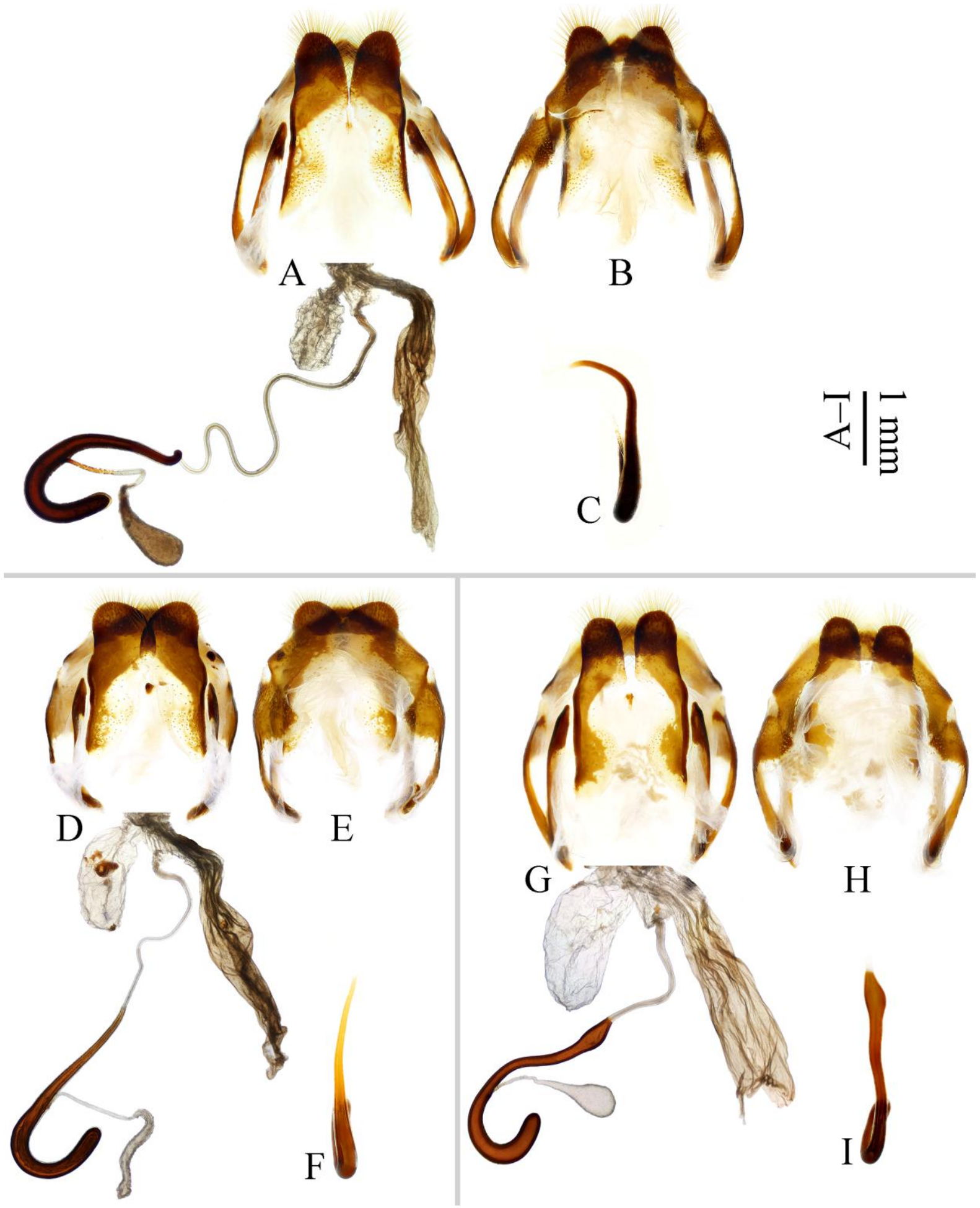

Figure 9. Female genitalia of Lucanus spp. A-C L. zhanbishengi sp. n. paratype c (Hunan) D-F L. brivioi Zilioli, 2003 (Fujian) G-I L. kraatzi Nagel, 1926 (Yunnan). A, D, G ventral view B, E, $\boldsymbol{H}$ dorsal view of hemisternites $\boldsymbol{C}, \boldsymbol{F}, \boldsymbol{I}$ right lateral view of spermathecae. 
Lucanus zhanbishengi sp. n., A New Species from Hunan, Central China (Coleoptera: Lucanidae: Lucaninae)

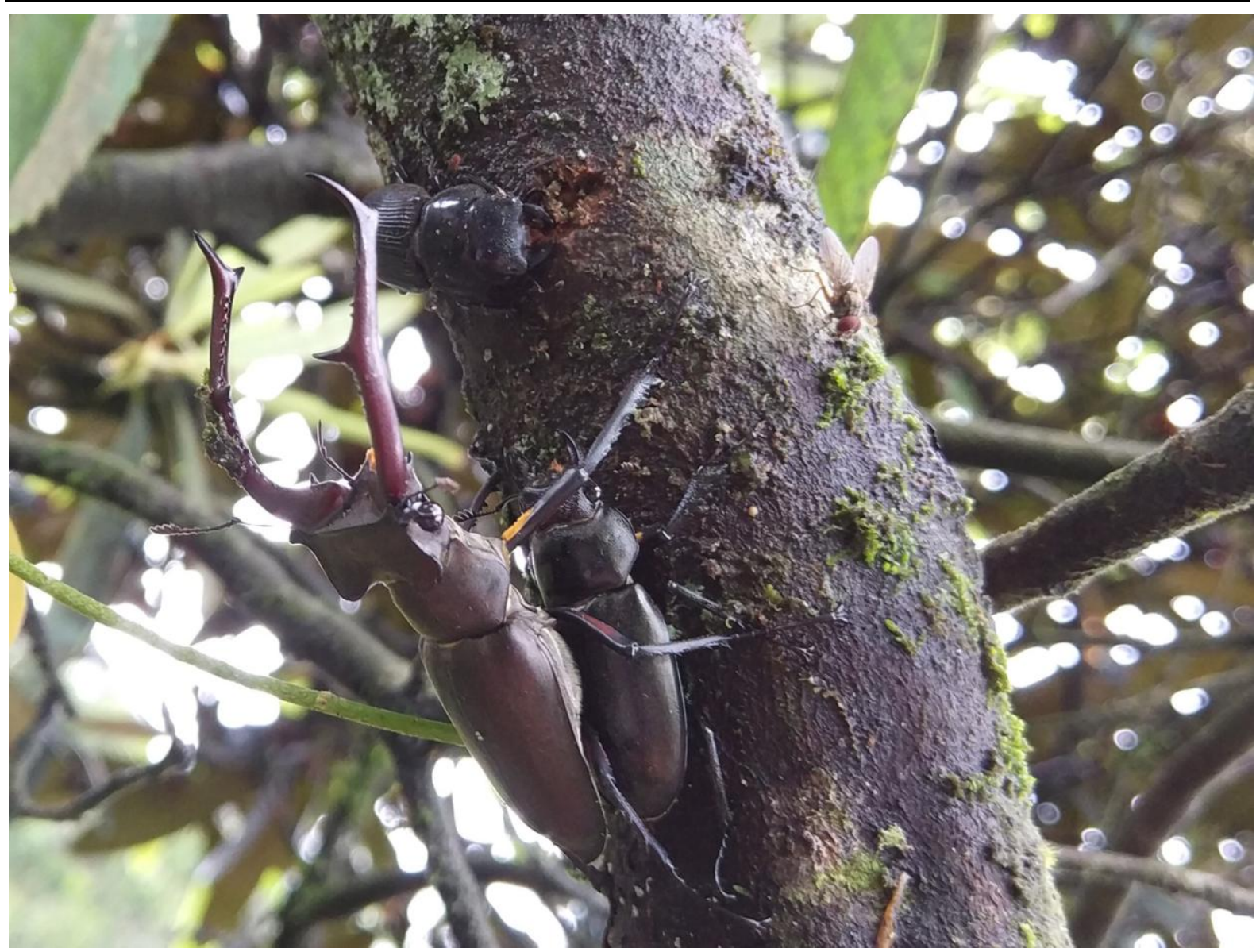

Figure 10. Field observations (Hunan: Xuefengshan Nature Reserve) of the mating behavior of Lucanus zhanbishengi sp. $n$. (Photoed by Bi-Sheng Zhan).

\section{ACKNOWLEDGEMENTS}

We would like to express our sincere gratitude to Bi-Sheng Zhan (Jiangsu University, Zhenjiang, Jiangsu, China) for donating most specimens of the new species. The first author especially thanks Bin Liu, an insect-obsessed eccentric on Cerambycidae, the founder and investor of Bin Insect Taxonomy Studio (Beijing, China), for his years of assistance and company. Our appreciation is due also to Chang-Chin Chen (Tianjin, China), Wen-I Chou (Taitung, Taiwan, China), Li He (Chengdu, Sichuan, China), Liang He (Institute of Zoology, Chinese Academy of Sciences, Beijing, China), Liang Lü (Hebei Normal University, Shijiazhuang, Hebei, China), Jan Růžička (Czech University of Life Sciences, Prague, Czech Republic), Hao Xu (Hunan Agricultural University, Changsha, Hunan, China), Xia Wan (Anhui University, Hefei, Anhui, China), Qiao-Zhi Yang (Beijing, China), Chao Zhou (Chengdu, Sichuan, China), Hong-Zhang Zhou (Institute of Zoology, Chinese Academy of Sciences, Beijing, China) for their considerable help in our study. We are obliged to Pavel Jakubec (Czech University of Life Sciences, Prague, Czech Republic) for helping with habitus photographs and with the camera system. We are grateful to Bin Liu, Bi-Sheng Zhan and Chao Zhou, reviewers who provided constructive comments on previous versions of the manuscript. This study was supported by the Bin Insect Taxonomy Studio (No. 2017).

\section{REFERENCES}

Boucher S (1998) Deux Lucanus inédits des provinces chinoises du Yunnan et du Guangxi (Coleoptera, Lucanidae). Coléoptères 4: 177-185.

Huang H, Chen C-C (2010) Stag beetles of China I. Formosa Ecological Company, Taipei, 288 pp. 
Lucanus zhanbishengi sp. n., A New Species from Hunan, Central China (Coleoptera: Lucanidae: Lucaninae)

Huang H, Chen C-C (2013) Stag beetles of China II. Formosa Ecological Company, Taipei, 716 pp.

Huang H, Chen C-C (2017) Stag beetles of China III. Formosa Ecological Company, Taipei, 524 pp.

Nagel P (1926) Neues über Hirschkäfer (Col. Lucanid.). Entomologische Mitteilungen 15: 116-121.

Zilioli M (2003) Lucanus brivioi n. sp., a new stag-beetle from the Wuyi shan mountains, Fujian, China

(Coleoptera Lucanidae). Atti della Società Italiana di Scienze Naturali e del Museo Civico di Storia Naturale di Milano 144: 265-272.

Citation: C.B. Wang \& X. Zhu, "Lucanus zhanbishengi sp. n., A New Species from Hunan, Central China (Coleoptera: Lucanidae: Lucaninae) ", International Journal of Research Studies in Zoology, vol. 3, no. 4, p. 54-69, 2017. http://dx.doi.org/10.20431/2454-941X.0304008

Copyright: (C) 2017 Authors. This is an open-access article distributed under the terms of the Creative Commons Attribution License, which permits unrestricted use, distribution, and reproduction in any medium, provided the original author and source are credited. 